\title{
Aplikasi Styrofoam Sebagai Absorpsi Bunyi
}

\author{
Allif Silfiyana Rohman ${ }^{(\mathrm{a})^{*}}$, Agus Yulianto ${ }^{(\mathrm{b})}$ dan Upik Nurbaiti ${ }^{(\mathrm{c})}$ \\ Jurusan Pendidikan Fisika, Universitas Negeri Semarang, Semarang, Indonesia, 50237 \\ Email: ${ }^{(a *)}$ silfiyanaallif830@gmail.com, ${ }^{(b)}$ yulianto566@mail.unnes.ac.id, \\ ${ }^{(c)}$ upiknurbaiti@mail.unnes.ac.id
}

Diterima (11 November 2021), Direvisi (03 Desember 2021)

\begin{abstract}
This study aims to determine the level of sound attenuation of Styrofoam material. This research is using a noise meter application Decibel X: $d B$ Sound Level Meter and a sound generator as a sound source. Styrofoam as an acoustic material with a thickness of $1 \mathrm{~cm} ; 1.5 \mathrm{~cm} ; 2 \mathrm{~cm} ; 2.5 \mathrm{~cm} ; 3 \mathrm{~cm} ; 3.5 \mathrm{~cm}$ and $4 \mathrm{~cm}$. The average absorption coefficient obtained in this study with a material thickness of $1 \mathrm{~cm}$ is 0.023 . Then the average absorption coefficient at a thickness of $1.5 \mathrm{~cm}$ is 0.031 . While the average absorption coefficient at a material thickness of $2 \mathrm{~cm}$ is 0.040 . Furthermore, the average sound absorption coefficient at a thickness of $2.5 \mathrm{~cm}$ and $3 \mathrm{~cm}$ has the same value, namely 0.039. Then, the average sound absorption coefficient at a thickness of $3.5 \mathrm{~cm}$ and $4 \mathrm{~cm}$ also has the same value, which is 0.038. Based on the research that has been done, it can be concluded that sound absorption at frequencies below $1000 \mathrm{~Hz}$ occurs significant sound absorption. At frequencies of $200 \mathrm{~Hz}, 400 \mathrm{~Hz}, 600 \mathrm{~Hz}$ and $800 \mathrm{~Hz}$, the average sound absorption increases from $1 \mathrm{~cm}$ to $3.5 \mathrm{~cm}$ of Styrofoam thickness. While the thickness of Styrofoam $4 \mathrm{~cm}$ on average did not show a significant increase in sound absorption. Styrofoam thickness of $4 \mathrm{~cm}$ can effectively absorb sound at a frequency of $1000 \mathrm{~Hz}$ only.
\end{abstract}

Keywords: Absorption, Sound, Styrofoam.

Abstrak. Penelitian ini bertujuan untuk mengetahui tingkat redam bunyi dari bahan Styrofoam. Penelitian ini menggunakan aplikasi pengukur kebisingan Decibel X:dB Sound Level Meter dan sound generator sebagai sumber bunyi. Styrofoam sebagai material akustik dengan ketebalan $1 \mathrm{~cm} ; 1,5 \mathrm{~cm} ; 2 \mathrm{~cm} ; 2,5 \mathrm{~cm} ; 3 \mathrm{~cm} ; 3,5$ $\mathrm{cm}$ dan $4 \mathrm{~cm}$. Rata-rata koefisien absorpsi yang diperoleh pada penelitian ini dengan ketebalan bahan $1 \mathrm{~cm}$ yaitu 0,023 . Kemudian rata-rata koefisien absorpsi pada ketebalan $1,5 \mathrm{~cm}$ yaitu 0,031 . Sedangkan rata-rata koefisien absorpsi pada ketebalan bahan $2 \mathrm{~cm}$ yaitu 0,040 . Selanjutnya, rata-rata koefisien absorpsi bunyi pada ketebalan bahan $2,5 \mathrm{~cm}$ dan $3 \mathrm{~cm}$ memiliki nilai sama yaitu 0,039 . Kemudian, rata-rata koefisien absorpsi bunyi pada ketebalan bahan $3,5 \mathrm{~cm}$ dan $4 \mathrm{~cm}$ juga memiliki nilai yang sama yaitu 0,038 . Berdasarkan penelitian yang telah dilakukan, dapat disimpulkan bahwa absorpsi bunyi pada frekuensi dibawah $1000 \mathrm{~Hz}$ terjadi absorpsi bunyi yang signifikan. Pada frekuensi $200 \mathrm{~Hz}, 400 \mathrm{~Hz}, 600 \mathrm{~Hz}$ dan $800 \mathrm{~Hz}$ rata-rata absorpsi bunyi semakin meningkat dari ketebalan Styrofoam $1 \mathrm{~cm}$ hingga $3,5 \mathrm{~cm}$. Sedangkan pada ketebalan Styrofoam $4 \mathrm{~cm}$ rata-rata tidak menunjukkan peningkatan absorpsi bunyi yang signifikan. Ketebalan Styrofoam $4 \mathrm{~cm}$ dapat efektif melakukan absorpsi bunyi pada frekuensi $1000 \mathrm{~Hz}$ saja.

Kata kunci: Absorpsi, Bunyi, Styrofoam.

\section{PENDAHULUAN}

Kemajuan teknologi semakin berkembang pesat para ilmuwan dan pengembang terus berlomba-lomba untuk menciptakan dan mengembangkan teknologi. Selain membawa dampak positif, kemajuan tenologi juga banyak membawa dampak negatif. Salah satu dampak negatif kemajuan teknologi adalah timbulnya polusi. Polusi bunyi atau kebisingan dapat menimbulkan konsekuensi jangka pendek dan jangka panjang bagi manusia, seperti berbagai bentuk stres, gangguan tidur, gangguan kognitif, tekanan darah tinggi, gangguan pendengaran, perkembangan penyakit kardiovaskular, pernapasan, dan sejenisnya [1]. Selain itu, orang yang hidup 
dalam kebisingan lalu lintas cenderung memiliki tekanan darah tinggi dibandingkan dengan orang yang hidup di tempat yang tenang [2].

Kemudian, bunyi mempunyai makna fisis dan fisiologis. Secara fisis, bunyi adalah penyimpangan tekanan, pergeseran partikel dalam medium elastik seperti udara sedangkan secara fisiologis, bunyi adalah sensasi pendengaran yang disebabkan penyimpangan fisis. Gelombang bunyi didefinisikan sebagai gelombang mekanik longitudinal berfrekuensi 20 sampai 20.000 $\mathrm{Hz}$ yang menjalar melalui medium elastis dan dapat ditangkap oleh indra dengar manusia [3].

Gelombang bunyi sangat penting peranannya dalam kehidupan manusia karena dengan gelombang bunyi manusia dapat saling berkomunikasi satu dengan lainnya. Getaran yang dihasilkan dari berbagai tekanan udara oleh sumber kebisingan dan disebarkan ke media sekitarnya yang dikenal sebagai medan akustik dan ketika suara menabrak batas media yang dilaluinya, maka energi dalam gelombang suara tersebut dapat ditransmisikan, diserap, atau dipantulkan oleh batas-batas [4].

Kebisingan tidak hanya mengganggu kenyamanan saat berkomunikasi, melainkan dapat juga berdampak buruk bagi kesahatan. Kebisingan yang cukup tinggi, di atas $85 \mathrm{~dB}$ dapat menyebabkan kemunduran serius pada kondisi kesehatan seseorang. Bila hal ini berkepanjangan dapat merusak pendengaran yang bersifat sementara maupun permanen [5].

Salah satu contoh kebisingan adalah suara sound sistem yang berada disebuah karaoke keluarga. Keluarga yang sedang berkaraoke disebuah tempat hiburan keraoke pun tanpa disadari juga dapat mengalami masalah kesehatan yang ditimbulkan oleh kebisingan [5]. Sedangkan menurut Hayat kebisingan adalah suara keras yang dapat ditimbulkan oleh berbagai jenis sumber bunyi seperti mesin pabrik, kendaraan, dan berbagai jenis suara yang ditimbulkan dalam intensitas tinggi dan mengganggu pendengaran [6]. Oleh karena itu, kebisingan merupakan bunyi yang tak beraturan sehingga dapat menimbulkan ketidaknyamanan.

Kebisingan secara berkelanjutan dapat mengakibatkan kerusakan pada telinga. Awalnya akan terjadi kehilangan pendengaran terhadap frekuensi tinggi, namun perlahan pada frekuensi yang semakin menurun sampai pada frekuensi terendah [7]. Orang yang hidup dalam kebisingan lalu lintas cenderung memiliki tekanan darah tinggi dibandingkan dengan orang yang hidup di tempat yang tenang [8]. Kebisingan dapat menimbulkan konsekuensi jangka pendek dan jangka panjang bagi manusia, seperti berbagai bentuk stres, gangguan tidur, gangguan kognitif, tekanan darah tinggi, gangguan pendengaran, perkembangan penyakit kardiovaskular dan pernapasan, dan sejenisnya [1]. Salah satu pertimbangan terpenting yang mendasari kriteria risiko kerusakan untuk paparan kebisingan dan yang mungkin kurang dipahami oleh masyarakat umum adalah tingkat risiko yang terkait dengan tingkat kebisingan tertentu bergantung pada durasi pemaparan [9].

Salah satu upaya yang dilakukan untuk mereduksi kebisingan yang terjadi pada suatu ruangan adalah dengan menggunakan material akustik [10]. Saat ini telah banyak upaya yang dilakukan untuk dapat mereduksi kebisingan pada suatu ruangan yaitu dengan menggunakan bahan-bahan peredam dan penyerap suara. Bahan tersebut dalam suatu bangunan biasanya berperan sebagai panel akustik yang dipasang pada dinding pemisah (partisi) dan plafon. Material penyerap bunyi mempunyai peranan penting dalam akustik ruangan, perancangan studio rekaman, ruang perkantoran, sekolah, dan ruang lain untuk mengurangi kebisingan yang 
umumnya sangat mengganggu. Material ini disebut material akustik yang fungsinya adalah untuk menyerap dan meredam suara [3].

Bahan penyerap suara sangat penting untuk mengontrol lingkungan suara, baik di lingkungan dalam gedung maupun di luar ruangan. Bahan penyerap suara dapat menyerap energi suara di dalam ruangan untuk mengurangi tingkat kebisingan [11]. Salah satu cara mencegah perambatan atau radiasi kebisingan adalah dengan menggunakan material akustik yang bersifat menyerap atau meredam bunyi sehingga bising yang terjadi dapat direduksi [12]. Material akustik adalah material teknik yang fungsi utamanya adalah untuk menyerap suara/bising. Material akustik dapat dibagi ke dalam tiga kategori dasar, yaitu: (1) material penyerap (absorbing material), (2) material penghalang (barrier material), (3) material peredam (damping material). Secara umum, bahan penyerap secara alami bersifat resistif, berserat dan berpori [4].

Banyak sekali jenis material akustik yang beredar di pasaran, akan tetapi harga yang ditawarkan cukup tinggi. Oleh karena itu, masyarakat yang hidup di wilayah perkotaan biasanya membuat partisi ruangan dengan bahan yang sederhana seperti triplek yang dilapisi dengan styrofoam. Styrofoam (busa polistiren) adalah busa plastik berbahan dasar minyak bumi. Umumnya styrofoam digunakan sebagai bahan peredam benda yang mudah terkena tekanan atau benturan, karena memiliki massa yang relatif ringan dan dapat membuat barang yang dilindungi aman dari benturan yang tidak diinginkan [4]. Styrofoam tidak hanya digunakan pada barang yang mudah pecah akan tetapi sebagai pelindung barang elektronika seperti televisi, dvd, dan lain sebagainya [5].
Proses penyerapan bunyi adalah ketika gelombang bunyi menumbuk material penyerap, maka energi bunyi sebagian akan diserap dan diubah menjadi panas. Bunyi akan masuk melalui pori-pori material dan menumbuk partikel-partikel di dalamnya. Kemudian, oleh partikel bunyi akan dipantulkan terus-menerus ke partikel lain sehingga bunyi akan terperangkap di dalam material [2]. Proporsi energi bunyi yang dipantulkan, diserap, atau diteruskan ditentukan oleh koefisien serap $(\alpha)$. Koefisien serap (absorpsi) adalah angka tanpa satuan yang menunjukkan perbandingan antara energi bunyi yang tidak dipantulkan (diserap) oleh material pembatas berbanding keseluruhan energi bunyi yang mengenai material pembatas. Bidang pembatas yang merupakan penyerap sempurna memiliki nilai koefisien serap 1, sementara yang memantulkan sempurna nilainya mendekati 0 [3].

Gelombang bunyi yang mengenai bidang batas, bergantung karakteristik permukaan bidang dan beberapa faktor lain. Besar kecilnya nilai koefisien serap selain bergantung frekuensi bunyi dan karakteristik material pembatas juga bergantung pada besarnya sudut jatuh gelombang bunyi [13].

Penyebaran gelombang juga mengakibatkan intensitas berkurang karena pertambahan luasanya, terkait dengan bentuk muka gelombang. Suatu gelombang menjalar dengan intensitas $\mathrm{I}_{0}$ sejauh $\mathrm{dx}$ dalam suatu medium yang mempunyai koefisien absorpsi $(\alpha)$ seperti pada Gambar 1. 


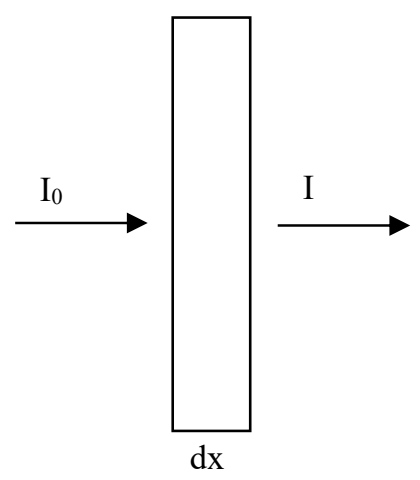

Gambar 1. Gelombang Menjalar Sejauh dx dalam Suatu Medium

maka besarnya penurunan intensitas atau atenuasi dapat ditulis seperti pada Persamaan 1.

$$
\begin{aligned}
& \mathrm{dI}=-\mathrm{I}_{0} \alpha \mathrm{dx} \\
& \frac{\mathrm{dI}}{\mathrm{I}_{0}}=-\alpha \mathrm{dx} \\
& \int \frac{\mathrm{dI}}{\mathrm{I}_{0}}=\int-\alpha \mathrm{dx} \\
& \ln \frac{\mathrm{I}}{\mathrm{I}_{0}}=\int-\alpha \mathrm{dx} \\
& \frac{\mathrm{I}}{\mathrm{I}_{0}}=e^{-\alpha \mathrm{x}} \\
& \mathrm{I}=\mathrm{I}_{0} e^{-\alpha \mathrm{x}}
\end{aligned}
$$

Efisiensi penyerapan bunyi suatu bahan pada frekuensi tertentu dinyatakan oleh koefisien absorpsi bunyi. Dari persamaan peurunan intensitas bunyi dapat ditemukan persamaan koefisien arbsorbsi bunyi seperti pada Persamaan 2:

$$
\begin{aligned}
\mathrm{I} & =\mathrm{I}_{0} \mathrm{e}^{-\alpha \mathrm{x}} \\
\ln \mathrm{I} & =\ln \left(\mathrm{I}_{0} \mathrm{e}^{-\alpha \mathrm{x}}\right) \\
\ln \mathrm{I} & =\ln \mathrm{I}_{0}+\ln \mathrm{e}^{-\alpha \mathrm{x}} \\
\ln \mathrm{I} & =\ln \mathrm{I}_{0}+(-\alpha \mathrm{x}) \ln \mathrm{e} \\
\ln \mathrm{I} & =\ln \mathrm{I}_{0}-\alpha \mathrm{x} \\
\alpha & =\frac{\ln \mathrm{I}_{0}-\ln \mathrm{I}}{\mathrm{x}}
\end{aligned}
$$

Terkait pemaparan tersebut peneliti mencoba melakukan penelitian tentang "Aplikasi Styrofoam Sebagai Absorpsi Bunyi". Penelitian ini bertujuan untuk mengetahui tingkat redam bunyi dari bahan Styrofoam. Manfaat yang diharapkan dengan adanya penelitian ini adalah untuk mendorong mahasiswa dan kalangan publik membuat alat berdasarkan konsep fisika yang dapat memecahkan permasalahan keterbatasan sumber daya energi. Selain itu juga mendapat pengetahuan tentang tingkat redam bunyi dari bahan Styrofoam.

Penelitian yang dilakukan oleh Jeon Chan-Ki styrofoam dapat digunakan sebagai bahan absorpsi pada knalpot sepeda motor karena karakteristiknya yang dapat didaur ulang, insulasi termal yang tinggi, insulasi suara yang sangat baik dan ringan [14]. Kemudian, menurut Sandi bahan yang kerap digunakan sebagai material absorben bunyi adalah styrofoam karena memiliki koefisien serap bunyi yang baik [15]. Sedangkan menurut Taban dengan meningkatkan ketebalan Styrofoam sebagai sampel akan secara langsung meningkatkan koefisien penyerapan suara pada rentang frekuensi rendah [16].

\section{METODOLOGI PENELITIAN}

Metode penelitian yang digunakan pada penelitian ini yaitu menggunakan aplikasi pengukur kebisingan Decibel $X: d B$ Sound Level Meter seperti yang dilakukan 
oleh Živković mengukur tingkat kebisingan pada 19 lokasi di Beograd yang dibagi menjadi empat zona yaitu zona pemukiman, zona dengan volume lalu lintas tinggi, zona rekreasi dan zona pusat kota [1]. Menurut studi yang dilakukan oleh Crossley dkk telah menunjukkan bahwa aplikasi iPhone Decibel $\mathrm{X}$ : $\mathrm{dB}$, dBA Noise Meter yang dapat diunduh gratis dapat memberikan bentuk penilaian tingkat kebisingan yang dapat diakses, hemat biaya, dan dapat diandalkan [17]. Perangkat ini dapat mewakili jaringan sensor yang murah namun kuat yang sudah tersedia dan digunakan secara luas serta dapat berfungsi sebagai sensor seluler yang dibawa oleh manusia daripada ditempatkan di lokasi statis [18]. Metode penelitian ini juga menggunakan variasi ketebalan material akustik seperti yang di lakukan oleh Taban dalam penelitiannya. Sampel dibuat dalam tiga ketebalan berbeda yaitu 25, 35 dan 45 $\mathrm{mm}$ [16]. Begitu juga dengan penelitian yang dilakukan oleh Thamrin sampel yang digunakan berbentuk silinder, dibuat sebanyak 4 buah dengan tebal $1,15 \mathrm{~cm}$; $1,95 \mathrm{~cm} ; 2,95 \mathrm{~cm}$ dan $4,05 \mathrm{~cm}$ [3].

Adapun langkah-langkah dalam penelitian ini yaitu menyiapkan seluruh alat dan bahan yang dibutuhkan; memotong styrofoam dengan ketebalan $1 \mathrm{~cm} ; 1,5 \mathrm{~cm}$; $2 \mathrm{~cm} ; 2,5 \mathrm{~cm} ; 3 \mathrm{~cm} ; 3,5 \mathrm{~cm}$ dan $4 \mathrm{~cm}$.; Merangkai seluruh alat seperti pada skema penelitian pada Gambar 2; Menyalakan sound generator melalui aplikasi pada smartphone yang telah terkalibrasi; Mengatur frekuensi sound generator sebesar $200 \mathrm{~Hz}$ di dalam box; Menyalakan sound level meter di dalam box; Mencatat intensitas suara yang tertera pada sound level meter.; Memasukkan styrofoam dengan ketebalan $1 \mathrm{~cm}$ sebagai bahan peredam.; Mencatat intensitas suara yang tertera pada sound level meter.; Mengulangi langkah-langkah tersebut menggunakan bahan peredam suara dengan ketebalan 1,5 $\mathrm{cm} ; 2 \mathrm{~cm} ; 2,5 \mathrm{~cm} ; 3 \mathrm{~cm} ; 3,5 \mathrm{~cm}$ dan $4 \mathrm{~cm}$.; Mengulangi langkah-langkah tersebut dengan mengubah frekuensi sound generator menjadi $400 \mathrm{~Hz}, 600 \mathrm{~Hz}, 800 \mathrm{~Hz}$ dan $1000 \mathrm{~Hz}$.

Decibel X untuk Android dan iOs adalah aplikasi pengukur kebisingan yang memberikan pengukuran tingkat suara prakalibrasi yang sangat andal dan mendukung dBA, dBC. Pengukuran dan grafik ditampilkan secara real-time serta frekuensi utama sehingga dapat digunakan di hampir semua kondisi [19].

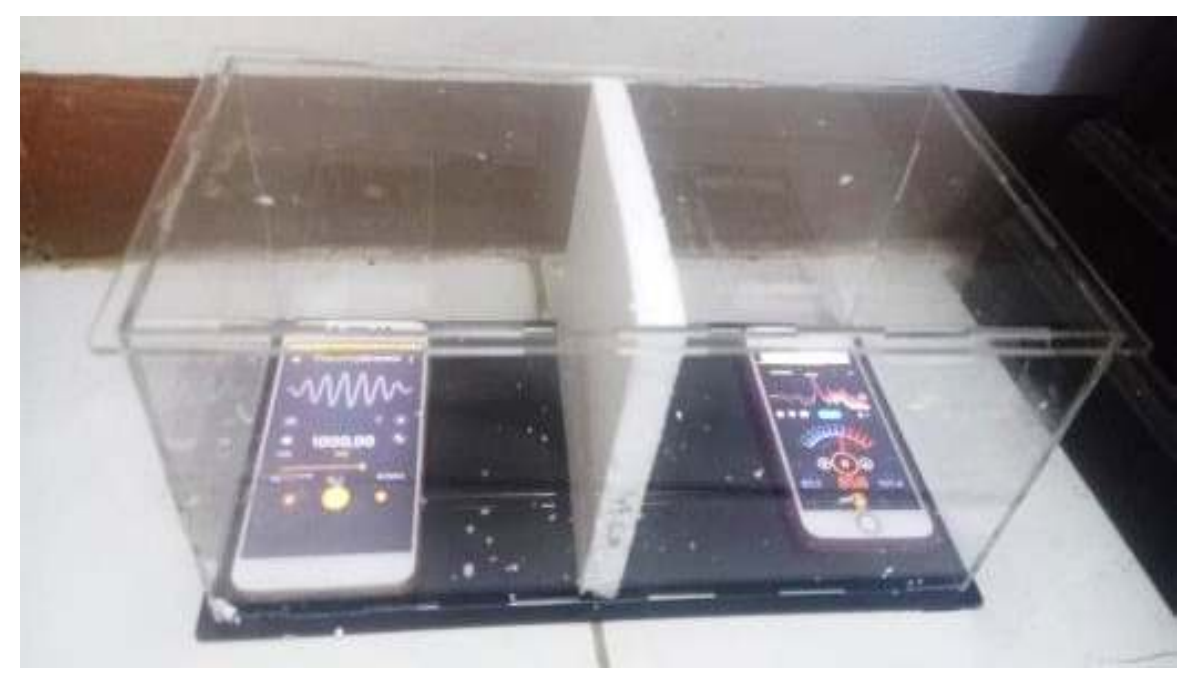

Gambar 2. Rangkaian Penelitian 
Menurut Roberts smartphone punya signifikansi nilai sebagai alat survei, dan sebagai Sound Level Meter di daerah sumber daya rendah. Selain itu, perangkat ini dapat digunakan untuk memetakan kebisingan lingkungan di suatu komunitas dengan memanfaatkan fungsi GPS smartphone. Akhirnya, seiring dengan peningkatan teknologi sensor, dimungkinkan untuk mengumpulkan data pada beberapa fisik bahaya sekaligus dengan menggunakan smartphone sebagai perangkat yang menyimpan dan mengekspor data dari sensor [20].

Penggunaan smartphone untuk mengukur kebisingan lingkungan, yang saat ini masih dalam tahap awal, memiliki potensi yang signifikan di masa depan untuk bertindak sebagai bentuk pemantauan kebisingan yang bersumber dari kerumunan [21]. Pertama, perangkat ini mewakili jaringan sensor yang murah namun kuat yang sudah tersedia dan digunakan secara luas. Kedua, dalam perspektif ini ponsel dapat berfungsi sebagai sensor seluler yang dibawa oleh manusia daripada ditempatkan di lokasi statis [18].

\section{HASIL DAN PEMBAHASAN}

Intensitas akhir bunyi pada masingmasing ketebalan bahan dengan frekuensi $200 \mathrm{~Hz}, 400 \mathrm{~Hz}, 600 \mathrm{~Hz}, 800 \mathrm{~Hz}$, dan 1000 $\mathrm{Hz}$ seperti pada Gambar 3. Keadaan ini sesuai dengan teori yang ada yaitu apabila suatu gelombang bunyi melewati medium fisik maka intensitas bunyi akan menurun sebanding dengan jarak yang ditempuh terhitung mulai terjadinya sumber bunyi tersebut. Peristiwa ini dikenal sebagai attenuasi [3].

Setelah dilakukan perhitungan koefisien arbsorbsi bunyi didapatkan nilai koefisien arbsorbi bunyi. Koefisien absorpsi bunyi pada masing-masing ketebalan bahan dengan frekuensi $200 \mathrm{~Hz}, 400 \mathrm{~Hz}, 600 \mathrm{~Hz}$, $800 \mathrm{~Hz}$,dan $1000 \mathrm{~Hz}$ seperti pada Gambar 4. Penelitian ini sesuai dengan prinsip dasar gelombang bunyi, gelombang dalam perambatanya akan mengalami penurunan intensitas (atenuasi) karena penyebaran dan penyerapan. Konsep dari penyerapan bunyi (Acoustic Absorption) merujuk kepada kehilangan energi yang terjadi ketika sebuah gelombang bunyi menabrak dan dipantulkan dari suatu permukaan benda.

Berdasarkan grafik pengukuran intensitas bunyi menunjukkan bahwa intensitas bunyi yang terukur setelah melewati material Styrofoam lebih rendah daripada sebelum melewati Styrofoam. Jika material Styrofoam semakin tebal maka intensitas bunyi yang terukur akan semakin kecil. Hal ini sesuai dengan teori yaitu apabila suatu gelombang bunyi melewati medium fisik maka intensitas bunyi akan menurun sebanding dengan jarak yang ditempuh terhitung mulai terjadinya sumber bunyi tersebut. Peristiwa ini dikenal sebagai attenuasi [3]. Pada frekuensi $200 \mathrm{~Hz}$ menggunakan ketebalan Styrofoam 1,5 cm mengalami penurunan koefisien absorpsi bunyi. Kemudian, pada ketebalan Styrofoam $4 \mathrm{~cm}$ juga tidak menunjukkan peningkatan absorpsi bunyi yang signifikan. Selanjutnya, pada frekuensi $400 \mathrm{~Hz}$ menggunakan ketebalan Styrofoam 1 sampai $3 \mathrm{~cm}$ menunjukkan absorpsi bunyi yang signifikan. Namun pada ketebalan 3,5 $\mathrm{cm}$ mengalami penurunan absorpsi bunyi. Sedangkan pada frekuensi $600 \mathrm{~Hz}$ dengan ketebalan Styrofoam 1 sampai $3,5 \mathrm{~cm}$ menunjukkan koefisien absorpsi bunyi yang signifikan dan mengalami penurunan absorpsi bunyi pada ketebalan $4 \mathrm{~cm}$. Pada frekuensi $800 \mathrm{~Hz}$ dengan ketebalan Styrofoam 1 sampai $3 \mathrm{~cm}$ mengalami peningkatan absorpsi bunyi yang signifikan dan mengalami penurunan absorpsi bunyi pada ketebalan 3,5 dan $4 \mathrm{~cm}$. Sedangkan pada frekuensi $1000 \mathrm{~Hz}$ kurang menunjukkan absorpsi bunyi yang signifikan hanya pada ketebalan $4 \mathrm{~cm}$ saja yang dapat melakukan adsopsi denga baik. 


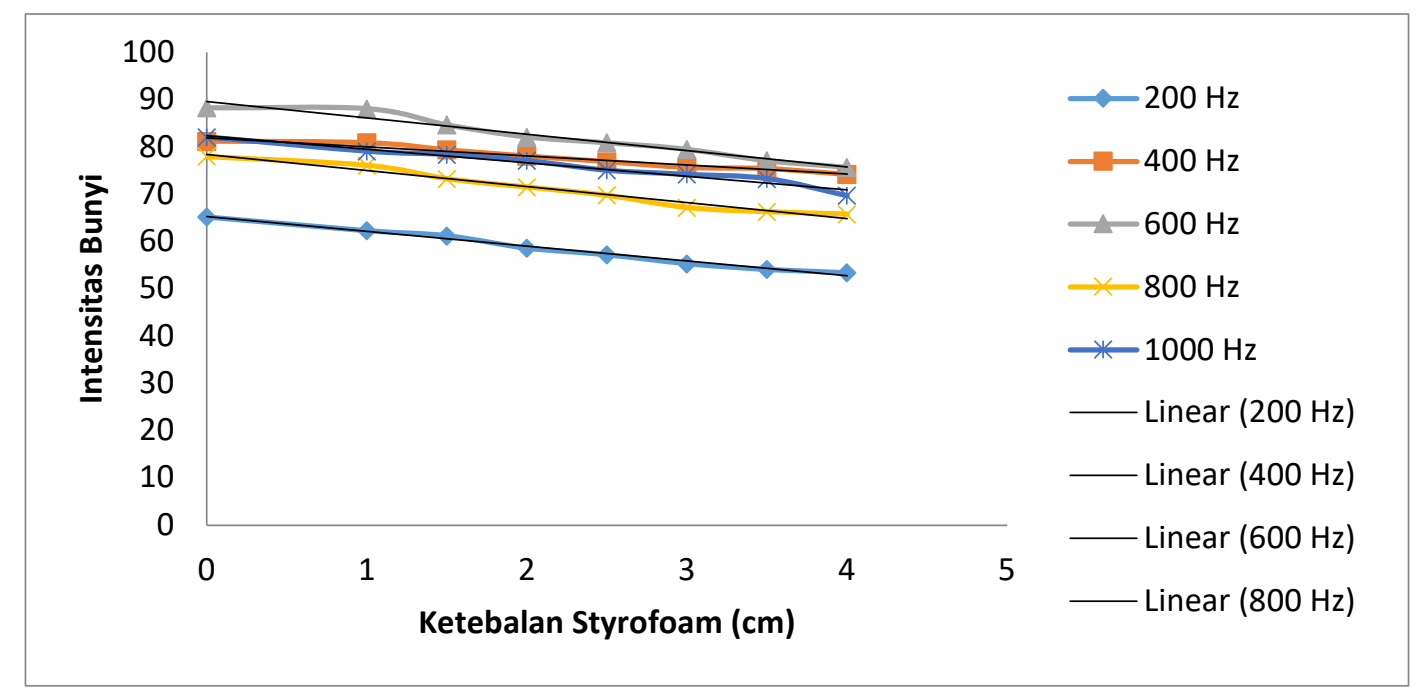

Gambar 3. Grafik Pengukuran Intensitas Bunyi

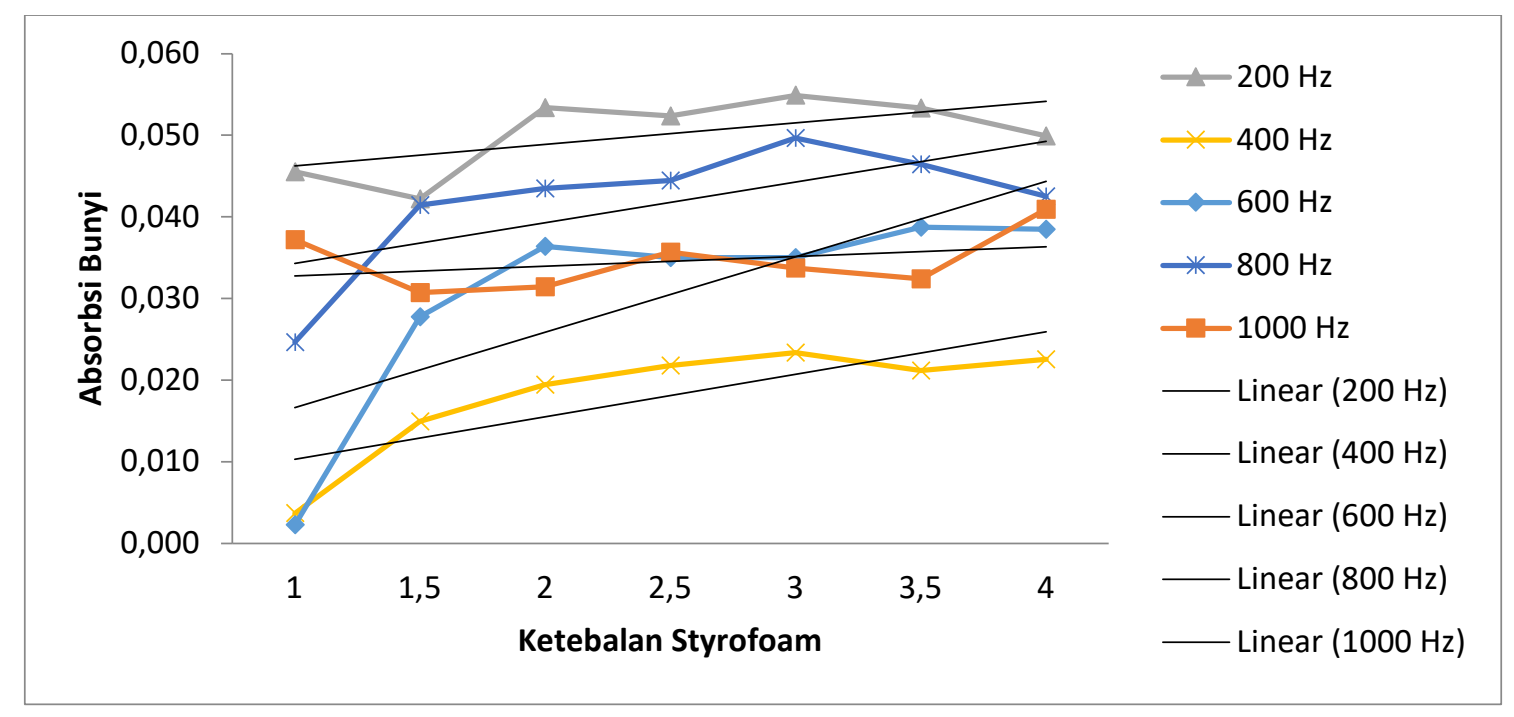

Gambar 4. Grafik Pengukuran Absorpsi Bunyi

Berdasarkan perhitungan koefisien absorpsi bunyi di peroleh data bahwa pada frekuensi $200 \mathrm{~Hz}, 400 \mathrm{~Hz}, 600 \mathrm{~Hz}$ dan 800 $\mathrm{Hz}$ rata-rata absorpsi bunyi semakin meningkat dari ketebalan Styrofoam $1 \mathrm{~cm}$ hingga $3,5 \mathrm{~cm}$. Sedangkan pada ketebalan Styrofoam $4 \mathrm{~cm}$ rata-rata tidak menunjukkan peningkatan absorpsi bunyi yang signifikan. Ketebalan Styrofoam $4 \mathrm{~cm}$ dapat efektif melakukan absorpsi bunyi pada frekuensi $1000 \mathrm{~Hz}$ saja. Seperti pada teori bahwa belum tentu semakin tebal sampel, koefisien serap bunyi pun ikut meningkat. Hal ini benar hanya untuk bunyi frekuensi rendah namun tidak selalu untuk frekeunsi tinggi [3].

Pada penelitian yang dilakukan oleh Thamrin, tentang koefisien serap bunyi dari bahan serbuk kayu kelapa menggunakan frekuensi $600 \mathrm{~Hz}$ menyimpulkan bahwa ketebalan sampel dapat mempengaruhi nilai koefisien serap bunyi $(\alpha)$. Koefisien serap bunyi $(\alpha)$ semakin menurun dengan bertambahnya ketebalan papan partikel 
(sampel penyerap) [3]. Sedangkan penelitian yang dilakukan oleh Jeon, Chan$\mathrm{Ki}$ menunjukkan bahwa styrofoam dapat digunakan sebagai bahan absorpsi pada knalpot sepeda motor karena karakteristiknya yang dapat didaur ulang, insulasi termal yang tinggi, insulasi suara yang sangat baik dan ringan [14].

Penelitian yang dilakukan oleh Taban, tentang karakterisasi penyerapan akustik dan prediksi serat sabut alami. Penelitian tersebut menunjukkan bahwa koefisien absorpsi suara pada sampel meningkat secara signifikan dengan meningkatnya frekuensi. Selain itu, peningkatan ketebalan material pada kepadatan konstan meningkatkan penyerapan suara, terutama pada frekuensi yang lebih rendah $(<1000$ $\mathrm{Hz}$ ). Perbandingan data eksperimen dan estimasi model menunjukkan bahwa dengan meningkatkan ketebalan, koefisien absorpsi akustik yang diprediksi untuk sampel menjadi lebih dekat dengan data dari pengujian eksperimen. Pada frekuensi $<1000 \mathrm{~Hz}$, meningkatkan celah udara di belakang sampel menjadi $3 \mathrm{~cm}$ akan meningkatkan nilai koefisien absorpsi suara. Sampel yang terbuat dari serat sabut akan secara efektif menghilangkan energi gelombang suara [16]. Kondisi tersebut sama dengan penelitian ini yaitu koefisien absorpsi bunyi pada frekuensi $200 \mathrm{~Hz}, 400$ $\mathrm{Hz}, 600 \mathrm{~Hz}$ dan $800 \mathrm{~Hz}$ rata-rata absorpsi bunyi semakin meningkat dari ketebalan Styrofoam $1 \mathrm{~cm}$ hingga $3,5 \mathrm{~cm}$.

Rata-rata koefisien absorpsi yang diperoleh pada penelitian ini dengan ketebalan bahan $1 \mathrm{~cm}$ yaitu 0,023 . Kemudian rata-rata koefisien absorpsi pada ketebalan $1,5 \mathrm{~cm}$ yaitu 0,031 . Sedangkan rata-rata koefisien absorpsi pada ketebalan bahan $2 \mathrm{~cm}$ yaitu 0,040 . Selanjutnya, ratarata koefisien absorpsi bunyi pada ketebalan bahan $2,5 \mathrm{~cm}$ dan $3 \mathrm{~cm}$ memiliki nilai sama yaitu 0,039 . Kemudian, rata-rata koefisien absorpsi bunyi pada ketebalan bahan $3,5 \mathrm{~cm}$ dan $4 \mathrm{~cm}$ juga memiliki nilai yang sama yaitu 0,038 .

Kemudian, penelitian yang dilkukan oleh Sandi dkk tentang pengukuran koefisien serapan bunyi spons dan styrofoam dengan menggunakan smartphone. Hasil pengukuran intensitas bunyi yang terukur setelah melewati sampel styrofoam dan spons memiliki pola penurunan yang bersifat eksponensial. Penelitian yang dilakukan menunjukkan bahwa koefisien serap bunyi styrofoam lebih tinggi dibandingkan dengan spons. Penggunaan smartphone yang dilengkapi dengan aplikasi berbasis sound generator dan aplikasi sound level meter berpotensi untuk diterapkan sebagai sistem pengukuran koefisien serap bunyi yang sederhana. Sehingga menurut Sandi dkk bahan yang kerap digunakan sebagai material absorben bunyi adalah styrofoam karena memiliki koefisien serap bunyi yang baik [15].

\section{KESIMPULAN}

Berdasarkan penelitian yang telah dilakukan, dapat disimpulkan bahwa pada frekuensi dibawah $1000 \mathrm{~Hz}$ terjadi absorpsi bunyi yang signifikan. Pada frekuensi 200 $\mathrm{Hz}, 400 \mathrm{~Hz}, 600 \mathrm{~Hz}$ dan $800 \mathrm{~Hz}$ rata-rata absorpsi bunyi semakin meningkat dari ketebalan Styrofoam $1 \mathrm{~cm}$ hingga $3,5 \mathrm{~cm}$. Sedangkan pada ketebalan Styrofoam $4 \mathrm{~cm}$ rata-rata tidak menunjukkan peningkatan absorpsi bunyi yang signifikan. Ketebalan Styrofoam $4 \mathrm{~cm}$ dapat efektif melakukan absorpsi bunyi pada frekuensi $1000 \mathrm{~Hz}$ saja.

Rata-rata koefisien absorpsi yang diperoleh pada penelitian ini dengan ketebalan bahan $1 \mathrm{~cm}$ yaitu 0,023 . Kemudian rata-rata koefisien absorpsi pada ketebalan $1,5 \mathrm{~cm}$ yaitu 0,031 . Sedangkan rata-rata koefisien absorpsi pada ketebalan bahan $2 \mathrm{~cm}$ yaitu 0,040 . Selanjutnya, ratarata koefisien absorpsi bunyi pada ketebalan bahan $2,5 \mathrm{~cm}$ dan $3 \mathrm{~cm}$ memiliki 
nilai sama yaitu 0,039 . Kemudian, rata-rata koefisien absorpsi bunyi pada ketebalan bahan $3,5 \mathrm{~cm}$ dan $4 \mathrm{~cm}$ juga memiliki nilai yang sama yaitu 0,038 .

\section{DAFTAR PUSTAKA}

[1] F. Zivkovic, "The Level of Ambient Sounds as an Indicator of Urban Road Safety," Put i saobraćaj, vol. 66 , no. 4, pp. 11-18, Dec. 2020, doi: 10.31075/pis.66.04.02.

[2] M. A. Fatkhurrohman and Supriyadi, "Tingkat Redam Bunyi Suatu Bahan (Triplek, Gypsum dan Styrofoam)," J. Fis., vol. 3, no. 2, pp. 138-143, Nov. 2013.

[3] S. Thamrin, S. H. . Tongkukut, and As'ari, "Koefisien Serap Bunyi Papan Partikel dari Bahan Serbuk Kayu Kelapa," J. MIPA UNSRAT, vol. 2, no. 1, pp. 56-59, Feb. 2013.

[4] S. Febrian, "Performance Study Between Polyurethane and Styrofoam as Diesel Engine Sound Insulating Materials on The Traditional Passenger Ship," J. Phys. Conf. Ser., vol. 1469, no. 1, Feb. 2020, doi: 10.1088/17426596/1469/1/012140.

[5] M. Munir and Dzulkiflih, "Pemanfaatan Fluk pada Styrofoam sebagai Bahan Dasar Peredam Suara dengan Metode Tabung Impedansi," J. Inov. Fis. Indones., vol. 04, no. 3, pp. 41-47, 2015.

[6] W. Hayat, Syakbaniah, and Y. Darvina, "Pengaruh Kerapatan Terhadap Koefisien Absorbsi Bunyi Papan Partikel Serat Daun Nenas(Ananas comosus L Merr)," Phillar Phys., vol. 1, pp. 44-51, 2013.
[7] D. Mayasari and R. Khairunnisa, "Pencegahan Noise Induced Hearing Loss pada Pekerja Akibat Kebisingan Prevention of Noise Induced Hearing Loss on Workers Due to Noise Expossure," J Agromed Unila, vol. 4, no. 2, pp. 354-360, Dec. 2017.

[8] W. I. N. Mukhlish, Y. Sudarmanto, and M. Hasan, "Pengaruh Kebisingan Terhadap Tekanan Darah dan Nadi pada Pekerja Pabrik Kayu PT. Muroco Jember," J. Kesehat. Lingkung. Indones., vol. 17, no. 2, pp. 112-118, Oct. 2018, doi: 10.14710/jkli.17.2.112-118.

[9] K. Mealings and E. F. Beach, "A Content Analysis of Behaviour Change Techniques In Noise Monitoring Apps," Hear. Heal. Technol. Matters, pp. 1-30, Nov. 2020.

[10] P. A. Tun, V. A. Williams, B. J. Small, and E. R. Hafter, "The Effects of Aging on Auditory Processing and Cognition," Am. J. Audiol., vol. 21, no. 2, pp. 344-350, 2012, doi: 10.1044/1059-0889(2012/12-0030).

[11] A. Kusno et al., "A Pilot Study on The Sound Absorption Characteristics of Chicken Feathers as an Alternative Sustainable Acoustical Material," Sustain., vol. 11, no. 5, Mar. 2019, doi: 10.3390/su11051476.

[12] Krisman, Defrianto, and D. M. Sinaga, "Pengukuran Koefisien Absorpsi Bunyi dari Limbah Batang Kelapa Sawit,"pp. 415-423.

[13] W. K. Kho, "Studi Material Bangunan yang Berpengaruh pada Akustik Interior," Dimens. Inter., 
vol. 12 , no. 2 , pp. $57-64$, Dec. 2014 , doi: 10.9744/interior.12.2.57-64.

[14] C. K. Jeon, J. S. Lee, H. Chung, J. H. Kim, and J. P. Park, "A Study on Insulation Characteristics of Glass Wool and Mineral Wool Coated With A Polysiloxane Agent," $A d v$. Mater. Sci. Eng., vol. 2017, pp. 1-7, Jan. 2017, doi: $10.1155 / 2017 / 3938965$.

[15] S. Kumalasari, J. Akbar, R. Sari, and F. Afriani, "Pengukuran Koefisien Serapan Bunyi Spons dan Styrofoam dengan Menggunakan Smartphone," J. Ris. Fis. Indones., vol. 1, no. 1, pp. 13-16, Dec. 2020, [Online]. Available:

http://journal.ubb.ac.id/index.php/jrfi /index/2011.

[16] E. Taban, A. Tajpoor, M. Faridan, S. E. Samaei, and M. H. Beheshti, "Acoustic Absorption Characterization and Prediction of Natural Coir Fibers," Acoust. Aust., vol. 47, no. 1, pp. 67-77, Apr. 2019, doi: 10.1007/s40857-019-00151-8.

[17] E. Crossley, T. Biggs, P. Brown, and T. Singh, "The Accuracy of iPhone Applications to Monitor Environmental Noise Levels,"
Laryngoscope, vol. 131, no. 1, pp. E59-E62, Jan. 2021, doi: 10.1002/lary.28590.

[18] N. Maisonneuve, M. Stevens, and B. Ochab, "Participatory Noise Pollution Monitoring Using Mobile Phones," Inf. Polity, vol. 15, no. 1-2, pp. 51-71, 2010, doi: 10.3233/IP2010-0200.

[19] A. Salandin, "Prappctices in Physics For Engineering Students," Stud. Educ. Manag., vol. 8, pp. 1-9, Dec. 2020, doi: 10.32038/sem.2020.08.01.

[20] B. Roberts, C. Kardous, and R. Neitzel, "Improving the Accuracy of Smart Devices to Measure Noise Exposure," J. Occup. Environ. Hyg., vol. 13, no. 11, pp. 840-846, Nov. 2016 , doi: 10.1080/15459624.2016.1183014.

[21] E. Murphy and E. A. King, "Testing The Accuracy of Smartphones and Sound Level Meter Applications for Measuring Environmental Noise," Appl. Acoust., vol. 106, pp. 16-22, May 2016, doi: 10.1016/j.apacoust.2015.12.012. 